metamorphosed and their developing lipoid Leydig cells were receptive to neurohumoral stimuli induced by the additional illumination.

The above-described tubule steatogenesis differs markedly from that which has long been known to occur in the semeniferous tubules of non-seasonal man. In adult man the abundant sudanophil material comes almost exclusively from changes in the Sertoli cells and not from cyclieal germ-cell breakdown. Further, unlike those of birds, the tubule lipoids of man are not cholesterol-positive (Marshall and Boswell, unpublished). It is of interest that during the single, restricted period of the year when the endocrine Leydig cells of the seasonal bird are very immature and wholly inactive, the lipoids within the neighbouring tubules give a strongly positive reaction for cholesterol, the probable precursor of the androgens. Further, an equally well-marked cholesterol reaction is obtained in atretic follicles of the regressed avian ovary.

Department of Zoology and A. J. Marshall Comparative Anatomy,

St. Bartholomew's Hospital Medical College, University of London, London, E.C.1.

Aug. 22 .

${ }^{1}$ Burger, W., Wilson Bull., 61, 4, 211 (1949).

2 Marshall, A. J., Quart. J. Mic. Sci., 90, 3, 265 (1949).

' Bissonnette, T. H., Wilson Bull., 49, 241 (1937).

4 Polikarpova, E., C.R. (Doklady) Acad. Sci. U.S.S.R., 27, 91 (1940). ${ }^{5}$ Morley, A., Ibis, 132 (April 1943).

'Bissonnette, 'T'. II., and Wadlund, A. P., J. Exp. Biol., 9, 4, 339 (1932).

- Riley, G. M., Proc. Soc. Exp. Biol. and Med., 34, 331 (1936).

\section{Growth Inhibition of a Yeast by Uracil, and its Reversal by Arginine}

ADENINE, guanine and uracil have been shown by Holland and Meinke ${ }^{1}$, to inhibit the growth of Streptococcus foecalis $\mathrm{R}$., the inhibition being reversed by serine. We have observed a similar inhibition of the growth of a yeast, Saccharomyces cerevisice strain D.C.L. 349, by uracil, which is reversed by arginine.

The synthetic medium used contained glucose, mineral salts, ammonia, biotin, pantothenic acid, aneurine, pyridoxine, inositol and nicotinamide, with or without adenine, guanine and xanthine. The addition of concentrations of uracil greater than $1.5 \times 10^{-5} \mathrm{M}$ to medium inoculated with $10 \mathrm{vgm} . / \mathrm{ml}$. of yeast 349 and shaken at $30^{\circ}$ inhibited the growth for about four days, whereas at $0 \cdot 1 \times 10^{-5}$ $M$ there was, in some cases, slight stimulation. Without uracil the yeast grew to completion in $24 \mathrm{hr}$. L-Arginine added at about one-third of the concentration of uracil completely reversed the inhibition over a range of $0.5-50 \times 10^{-5} \mathrm{M}$. DL-Citrulline at concentrations forty times greater had a similar action to L-arginine. The inhibitory effect was not counteracted by twenty other amino-acids, including ornithine, added singly or in combination, or by folic acid, urea, or the guanidine bases glycocyamine, creatine, agmatine and guanidine. The growth of nine other yeasts, S. cerevisice strain D.C.L. 211, $S$. cerevisice strain alpinus, S. carlsbergensis 4428, S. macedoniensis, S. logos, S. fragilis, Torula colliculosa, $T$. cremoris and Kloeckera brevis, was slightly stimulated by uracil, rather than depressed. The specificity of the action of uracil was tested by substituting the following related compounds, none of which showed a similar effect : namely, alloxan, alloxantin, allantoin, cytidine, isocytosine, barbituric acid, iso-barbituric acid, orotic acid, 5-amino-uraeil, 5-nitro-barbituric acid, dialuric acid, violuric acid, iso-violuric acid, 2-thiouracil, 2-methyl-4-amino-5-ethoxymethyl-pyrimidine and thymine.

In view of a similar antagonism described by Volcani and Snell ${ }^{2}$ between arginine and its structural homologue canavanine, a sample of canavanine, kindly given by Dr. C. J. O. R. Morris, was tested and found to inhibit the growth of typical strains of the genera of yeasts mentioned above, and in all cases the effect was reversed by arginine. Hence it is concluded that canavanine effects a mechanism which is common to most yeasts, whereas the action of uracil is of a more specific nature.

\section{E. J. MILLER}

J. S. HARRISON

Research and Development Department,

The Distillers Co., Ltd.,

Epsom, Surrey. July 31.

${ }^{1}$ Holland, B. R., and Meinke, W. W., J. Biol. Chem., 178, 7 (1949).

2 Volcani, B. E., and Snell, E. E., J. Biol. Chem., 174, 893 (1948).

\section{Phase Coloration in Larva of Lepidoptera}

АвоUт thirty years ago Uvarov brought forward the 'phase' theory of locusts and showed that young hoppers when crowded together developed differences in colour, structure, behaviour and physiology from similar larvæ kept individually separate. The former were known as the phase 'gregaria' and the latter as 'solitaria'. Gregaria are always darker in colour than solitaria.

In 1943 Faure announced the discovery of phases in larvæ of two South African Lepidoptera of the family Noctuidæ, Laphygma exigua (the lesser army worm) and $L$. exempta (the army worm), with the possibility of its occurrence in a third species Spodoptera abyssinia.

We have recently carried out two repetitions of an experiment on larvæ of Plusia gamma (the silver-Y moth), in each case from a single batch of eggs, some of the larvæ crowded and others kept solitary. All the solitary caterpillars remained pale green, while the crowded larvæ changed from a green darker than that of the solitaries to an extremely dark coloration. These laboratory experiments are supported also by some field observations (which led to the investigation) in which unusually dark larvæ were associated with mass outbreaks.

It is curious to note that, with the exception of S. abyssinia, all the Lepidoptera in which phases have been demonstrated are migratory species, similar to the locusts, but why there should be the connexion and if it is more general cannot yet be answered.

Further experiments are now in progress on the chemical and physical aspects of the physiological differences, and on the behaviour patterns, in $P$. gamma and also in other species such as Pieris brassicce (the large cabbage white butterfly), which is a well-known migrant, and other non-migratory Lepidoptera.

Fuller details will be published later.

$$
\text { C. B. Williams }
$$

Department of Entomology,

Rothamsted Experimental Station, Harpenden, Herts. July 30 . 